\title{
Sertraline concentrations in pregnant women are steady and the drug transfer to their infants is low
}

\author{
E. Heinonen ${ }^{1,2}\left(\mathbb{D} \cdot\right.$ M. Blennow $^{1,2} \cdot$ M. Blomdahl-Wetterholm $^{3} \cdot$ M. Hovstadius $^{1} \cdot$ J. Nasiell $^{4,5} \cdot$ A. Pohanka ${ }^{6,7}$. \\ L. L. Gustafsson ${ }^{6,7} \cdot$ K. Wide W,8 $^{1,8}$
}

Received: 24 November 2020 / Accepted: 9 March 2021 / Published online: 22 March 2021

(C) The Author(s) 2021

\begin{abstract}
Purpose Sertraline, a selective serotonin reuptake inhibitor (SSRI), is one of the most commonly used antidepressant during pregnancy. Plasma sertraline concentrations vary markedly between individuals, partly explained by variability in hepatic drug metabolizing cytochrome P450-enzyme activity. Our purpose was to study the variability in the plasma concentrations in pregnant women and the passage to their infants.

Method Pregnant women with moderate untreated depression were recruited in 2016-2019 in Stockholm Region and randomized to treatment with sertraline or placebo. All received Internet-based cognitive behavior therapy as non-medical treatment. Sertraline plasma concentrations were measured around pregnancy weeks 21 and 30, at delivery, 1-month postpartum, in cord blood and at $48 \mathrm{~h}$ of age in the infant. The clinical course of the infants was followed.

Results Nine mothers and 7 infants were included in the analysis. Median dose-adjusted sertraline concentration in second trimester was $0.15(\mathrm{ng} / \mathrm{mL}) /(\mathrm{mg} /$ day $)$, in third trimester and at delivery 0.19 and 1 -month postpartum 0.25 , with a $67 \%$ relative difference between second trimester and postpartum. The interindividual variation was 10-fold. Median concentrations in the infants were $33 \%$ and $25 \%$ of their mothers', measured in cord blood, and infant plasma, respectively. Only mild and transient adverse effects were seen on the infants.

Conclusion Placental passage of sertraline to the infant is low. However, the interindividual variation in maternal concentrations during pregnancy is huge, why therapeutic drug monitoring might assist in finding the poor metabolizers at risk for adversity and increase the safety of the treatment.
\end{abstract}

Trial registration The trial was registered at clinicaltrials.gov July 9, 2014 with TRN: NCT02185547.

\author{
E. Heinonen \\ essi.heinonen@ki.se \\ M. Blennow \\ mats.blennow@ki.se \\ M. Blomdahl-Wetterholm \\ margareta.blomdahl-wetterholm@sll.se \\ M. Hovstadius \\ malin@hovstadius.com \\ J. Nasiell \\ josefine.nasiell@ki.se
A. Pohanka
anton.pohanka@sll.se
L. L. Gustafsson
lars-l.gustafsson@ki.se
K. Wide
katarina.wide@ki.se

1 Division of Paediatrics at the Department of Clinical Science, Intervention and Technology (CLINTEC), Karolinska Institute, Stockholm, Sweden

2 Department of Paediatrics and Newborn Medicine, Karolinska University Hospital, Stockholm, Sweden

3 Psychiatry South West, Stockholm Healthcare Region, Stockholm, Sweden

4 Department of Clinical Sciences, Danderyd Hospital, Karolinska Institute, Stockholm, Sweden

5 Department of Obstetrics and Gynaecology, Danderyd Hospital, Stockholm, Sweden

6 Division of Clinical Pharmacology at the Department of Laboratory Medicine, Karolinska Institute, Stockholm, Sweden

7 Department of Clinical Pharmacology, Karolinska University Hospital, Stockholm, Sweden

8 Department of Paediatrics and Emergency Paediatrics, Karolinska University Hospital, Stockholm, Sweden 
Keywords Antenatal depression · Infant · Pharmacokinetics · Pregnancy $\cdot$ Selective serotonin reuptake inhibitors $\cdot$ Therapeutic drug monitoring

\section{Introduction}

Sertraline is one of the most commonly used selective serotonin reuptake inhibitors (SSRI) during pregnancy, and generally proven safe for this use [1-6]. Plasma sertraline concentrations are shown to both increase and decrease during pregnancy [7-9]. No clear association has been found between the dose of sertraline or the plasma sertraline concentration and the clinical effect [10-15]. Plasma sertraline concentrations seem to vary up to 10 -fold between individuals, but with a low intraindividual variation, with a recommended therapeutic range of $10-50 \mathrm{ng} / \mathrm{mL}[12,16,17]$. The inter- and intraindividual variations seem similar in pregnant and nonpregnant populations.

Sertraline and desmethylsertraline are weak basic compounds. Sertraline is over $98 \%$ protein bound in plasma, binding to both albumin and alfa 1-acid-glycoprotein (AAP), but most likely mainly to AAP [18-20]. The levels of both albumin and AAP decrease during pregnancy, potentially affecting the sertraline plasma concentrations [21]. Multiple Cytochrome P450 (CYP) enzymes in the liver metabolize sertraline to its main weakly active metabolite Ndesmethylsertraline [22]. The activity of these enzymes is genetically coded [23]. Current consensus is that CYP2C19 has a major role in sertraline metabolism and that the genetic differences in its expression cause interindividual variability in sertraline concentrations. The importance of CYP2B6, CYP3A4, CYP2C9, and CYP2D6 for the disposition of sertraline in vivo is not yet clear [22, 24-26]. Pregnancy induces changes in metabolic enzyme activity, with the activity of CYP2C19 being slightly down-regulated, and the activities of the other potentially important enzymes being upregulated [7-9, 21]. As the pharmacokinetics change during pregnancy, therapeutic drug monitoring (TDM) might be a way to improve both safety and efficacy of the treatment $[7$, $12,16,17]$.

The infant albumin level at birth is slightly higher than the maternal, whereas the level of AAP is only a third of the mothers [27]. In previous studies, the placental penetration of sertraline to infant serum has seemed low, with infantmother ratios at around $0.3-1.0$ reported [25, 28-32]. Transient neonatal effects such as jitteriness, hypoglycemia, and respiratory disorders are described after intrauterine SSRI exposure [33, 34].

Designing a randomized controlled trial, we aimed to clarify several aspects of the effects of antidepressant treatment on the pregnant mother and her infant. In this pharmacokinetic part of the study, we aimed to clarify the variability in plasma sertraline concentrations during pregnancy and demonstrate whether TDM would improve the safety and efficacy of the treatment. In the infant, we aimed to measure the plasma levels of sertraline and relate these to the maternal concentrations and potential clinical symptoms in the new born.

\section{Materials and methods}

\section{Clinical design and methods}

This study is part of a double-blind randomized controlled trial examining the effects of sertraline and depression in pregnancy on the short- and long-term outcomes in the infants, the MAGDALENA study. The study design is fully described in the study protocol publication [35], and details on the recruitment, randomization, and follow-up are presented in the online supplement. All patients had an untreated moderate major depressive disorder at inclusion. Women with psychiatric or somatic comorbidities or any chronical drug treatment were excluded from the study. All included women were offered a 12-week program of Internet-based cognitive behavior therapy (I-CBT) with pregnancy-adapted treatment modules developed by our team [36]. Additionally, the women were either randomized to sertraline or placebo with the daily dose starting at one capsule á $25 \mathrm{mg}$. The treatment effect was followed up by the Montgomery Åsberg Depression Scale (MADRS) at the follow-up visits with the study midwife $[37,38]$. The dose was increased in steps of one capsule when lacking treatment response, up to a dose of four capsules (100 mg of sertraline vs placebo). If patients in the placebo arm did not improve despite the I-CBT treatment, they were unblinded and switched to treatment with sertraline.

This pharmacology part of the study describes the sixteen included mother-infant-pairs, focusing on the nine mothers who in the end received treatment with sertraline (Suppl.Fig.1). Plasma sertraline and desmethylsertraline concentrations in the mothers were measured once in the second trimester around week 21 (range 17-25) of pregnancy and once in the third trimester around week 30 (range 26-36) of pregnancy, the morning after the delivery and 1-month postpartum. The infant concentrations are measured in cord blood and at $48 \mathrm{~h}$ of age together with the routine neonatal screening (Table 2, Fig. 1). All concentrations are steady-state total plasma concentrations. The babies were monitored with the modified Neonatal Abstinence Scale (NAS) according to Finnegan [39] during their first $48 \mathrm{~h}$ of life, and their plasma glucose concentrations (p-glucose) were measured at 6 and $48 \mathrm{~h}$ of age. 
Fig. 1 a, b Boxplots of the penetration ratios of sertraline (a) and desmethylsertraline (b). a) Penetration ratio of sertraline into cord blood (CB/MP, 5 motherinfant pairs): median 0.33; IQrange $0.24-0.58$; range: 0.14 1.17 , and infant plasma (IP/MP, 5 mother-infant pairs): median 0.25; IQ-range 0.23-0.26; range $0.16-0.49$. b) Penetration ratio of desmethylsertraline into cord blood (CB/MP, 5 mother-infant pairs): median 0.29; IQ-range $0.28-0.36$; range: $0.24-1.42$, and infant plasma (IP/MP, 5 motherinfant pairs); median 0.34, IQrange $0.31-0.37$; range $0.31-0.46$ a

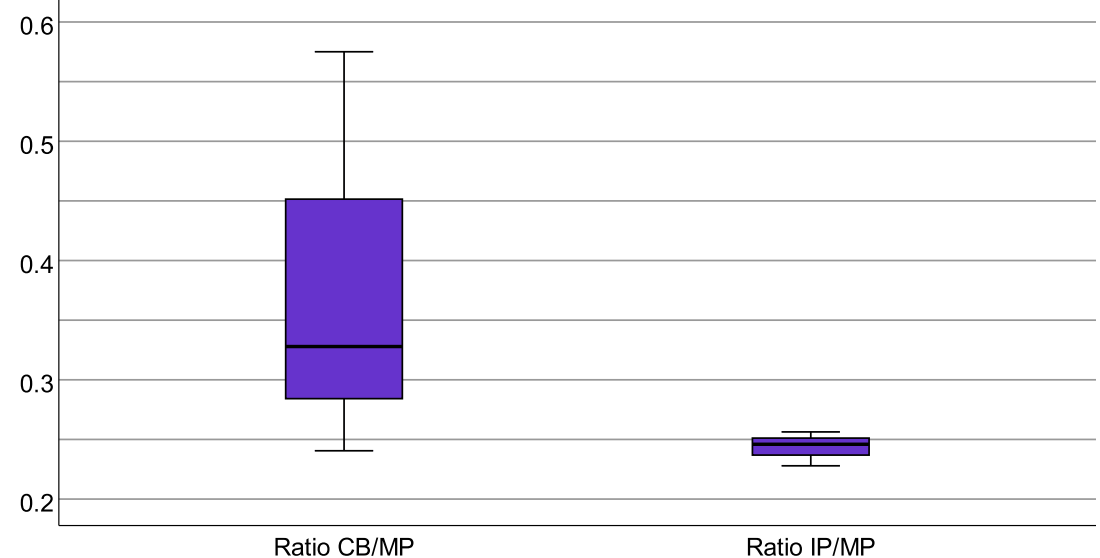

b

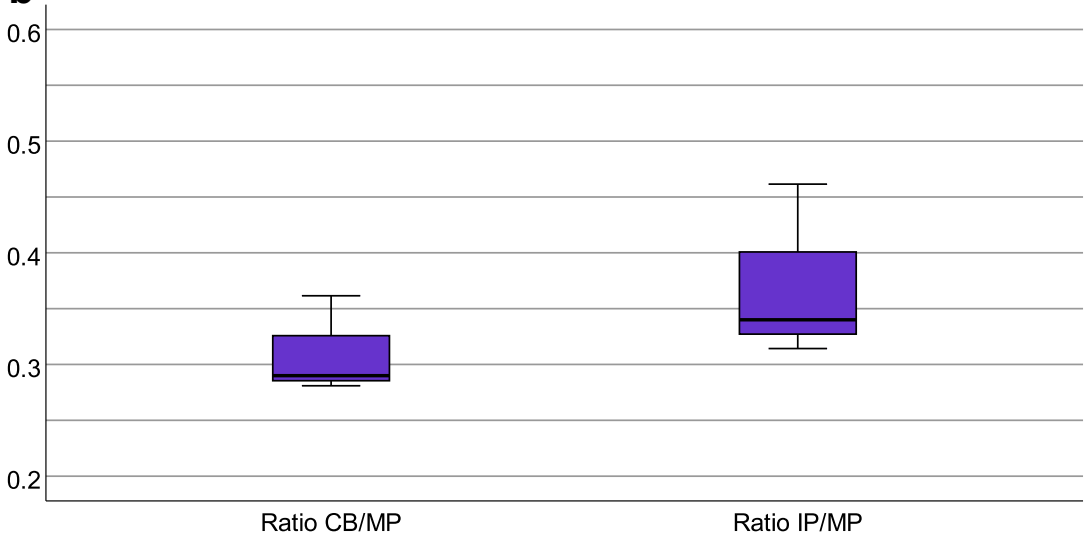

\section{Laboratory methods}

Four milliliters of venous blood was collected from the women at each visit and from the umbilical cord at delivery into sodium heparin tubes. From the infants, $0.5 \mathrm{~mL}$ venous blood was collected at $48 \mathrm{~h}$ of age into lithium heparin capillary tubes. The drug analytical laboratory method and its performance are described in detail in the online supplement.

\section{Statistical analysis}

Plasma concentrations originally presented in molar units $(\mathrm{nmol} / \mathrm{L})$ were converted to mass units $(\mathrm{ng} / \mathrm{mL})$ by multiplying the molar unit with the molecular weights of sertraline, $306.2 \mathrm{~g} / \mathrm{mol}$, and desmethylsertraline, $292.2 \mathrm{~g} / \mathrm{mol}$, to achieve the concentrations in $\mathrm{ng} / \mathrm{L}$ and dividing by 1000 to achieve the concentrations in $\mathrm{ng} / \mathrm{mL}$ [40]. A concentration-by-dose (C/D) ratio in $(\mathrm{ng} / \mathrm{mL}) /(\mathrm{mg} /$ day $)$ was calculated by dividing the achieved concentration by the daily dose of sertraline in milligrams. Alteration ratios (AR) were used to analyze the difference between maternal plasma concentrations in the pregnant and the non-pregnant state, in accordance with previous studies [41]. Alteration ratios were calculated for the measuring points in pregnancy and at delivery by dividing these dose-adjusted concentrations with their non-pregnant reference, measured 1-month postpartum. Due to the nature of these analyses, the data were analyzed per protocol, and women were moved between treatment groups when treatment regime changed. To explore the foetal exposure, correlations was calculated between the concentration in maternal plasma and the ones in cord blood and infant plasma. The penetration ratio into cord blood (CB) and infant plasma (IP) was calculated by dividing the concentration in cord blood or infant plasma with the concentration in maternal plasma (MP), reflecting the penetration ratio into the infant.

Data is presented as medians, interquartile (IQ) ranges between the first(Q1) and the third(Q3) quartiles as well as ranges between min and max values. Correlations were computed to assess the relationship between the drug concentrations in maternal plasma and the infant. Because of the linearity of this correlation (Supp. Fig. 3), Pearson's correlation coefficients were calculated. When searching for statistical significance in the decreased sertraline concentrations during pregnancy compared to postpartum, the non-parametric Wilcoxon's signed rank test was used due to the small sample size. The non-parametric Spearman's correlation test was used to study the correlation between the sertraline concentration and the treatment effect in the pregnant women (Section 2.2 of 
the online supplement). Statistical analyses were conducted with SPSS (version 26, IBM, Armonk, NY, USA).

\section{Results}

\section{Patient characteristics}

The study cohort consisted of 16 women recruited between May 2016 and March 2019. Ten women were randomized to sertraline and six to placebo treatment. In the end, nine women with two or more available sertraline plasma concentrations are included in the analysis (Table 2, Table 3, Supplemental Fig. 2). The randomization procedure and the flowchart of the study are described in detail in the online supplement (Supplemental Fig. 1). In two cases, infant drug concentrations are missing or lacking informed consent from the other parent, leading to seven mother-infant-pairs being analyzed for placental cross-over (Fig. 1, Supplemental Fig. 3).

Concomitant medications are presented in supplementary Table 1 . The only concomitant psychotropic drug was promethazine, a first-generation antihistamine used temporarily by three women in the study. Temporary use of promethazine during pregnancy for pregnancy-related nausea and anxiety is common.

\section{Sertraline and desmethylsertraline plasma concentrations during pregnancy}

The repeated concentration measures of sertraline and desmethylsertraline show an up to 10 -fold interindividual variation (Table 2). The intraindividual dose-adjusted measures seem fairly consistent over the course of pregnancy with an increase postpartum, visualized in the line graph in supplemental Figure 2 (Table 2, Supplemental Fig. 2). The median dose-adjusted sertraline concentration increased with $67 \%$ from 0.15 to $0.25(\mathrm{ng} / \mathrm{mL}) /(\mathrm{mg} /$ day $)$ from the second trimester to postpartum, but the variation was large, and the increase was not statistically significant $(p=0,345)$ (Table 2$)$. The increase over time in the non-dose-adjusted concentrations might be related to the study design with increased dosage during pregnancy in most patients. We studied the correlation between plasma sertraline concentrations and treatment effect measured with a change in MADRS, without finding any significant correlations. This is further described in the online supplement, Section 2.2.

\section{Alteration ratios}

We calculated alteration ratios between pregnant and nonpregnant state on the 8 patients with available non-pregnant reference concentrations measured 1-month postpartum. The median alteration ratio for sertraline during pregnancy is 0.83 and for desmethylsertraline 0.82 , with an almost 10 -fold variation in both (Table 3).

\section{Infant sertraline exposure}

The median concentration of sertraline in maternal plasma at delivery $(n=8)$ was $14.38 \mathrm{ng} / \mathrm{mL}$ (range 3.64-24.17), and the median concentrations in the infants were $4.28 \mathrm{ng} / \mathrm{mL}$ (range 1.22-6.12) in cord blood $(n=5)$ and $4.59 \mathrm{ng} / \mathrm{mL}$ (range 1.25 $7.04)$ in infant plasma at $48 \mathrm{~h}$ of age $(n=5)$. The median concentration of desmethylsertraline in maternal plasma at delivery $(n=8)$ was $33.60 \mathrm{ng} / \mathrm{mL}$ (range 7.01-31.36). Median concentrations in the infants were $9.93 \mathrm{ng} / \mathrm{mL}$ (range 4.96-17.23) in cord blood $(n=5)$ and $17.52 \mathrm{ng} / \mathrm{mL}$ (range 9.93-20.44) in infant plasma at $48 \mathrm{~h}$ of age $(n=5)$. We confirmed the concentrations being generally lower in the infants than in their mothers by calculating penetration ratios into cord blood (CB) and infant plasma (IP) (Fig. 1). Figure 1 also show a decreased ratio of sertraline and an increased ratio of desmethylsertraline between the samples measured from cord blood and in infant plasma at $48 \mathrm{~h}$ of age, indicating clearance of sertraline and conversion into desmethylsertraline within the first $48 \mathrm{~h}$ of life.

The correlations between the sertraline and desmethylsertraline concentrations in maternal plasma and the infant are fairly linear, as presented in supplemental Fig. 3. The Pearson correlation coefficients for these correlations were $r=0.70(p=0.19)$ for the correlation of sertraline concentration between maternal plasma and cord blood, $r=0.64$ $(p=0.24)$ for sertraline concentration between maternal and infant plasma, $r=0.78(p=0.12)$ for desmethylsertraline concentration between maternal plasma and cord blood, and $r=0.83(p=0.08)$ for desmethylsertraline concentration between maternal and infant plasma.

\section{Neonatal outcomes}

All infants are healthy at birth, with all $5^{\prime}$ and $10^{\prime}$ APGAR scores being 9 or 10 (Table 1). No baby showed any signs of severe withdrawal symptoms, classified as NAS $>8$ points. One baby in the placebo group shows signs of moderate abstinence (NAS 7 points), and two babies in the sertraline treatment group show signs of mild abstinence (NAS 4 points), but none required any treatment for this (Table 1). One baby in the sertraline treatment group presented with a single low p-glucose of $2.5 \mathrm{mmol} / \mathrm{L}$ before the second feed but did not require any additional treatment apart from extra feeding. No other babies signs of hypoglycemia. One baby in the sertraline group was born preterm at 33 weeks of gestation and was the only baby who needed neonatal care. This baby did not have any complications from the premature birth. One baby in the placebo 
Table 1 Patient characteristics and delivery outcomes

\begin{tabular}{|c|c|c|c|c|c|c|c|c|c|c|}
\hline Patient & Assignedtreatment & $\begin{array}{l}\text { Maximal dose of } \\
\text { Sertraline (mg) }\end{array}$ & $\begin{array}{l}\text { Maternal age } \\
\text { (years) }\end{array}$ & $\begin{array}{l}\text { GA } \\
(w+d)\end{array}$ & Delivery mode & $\begin{array}{l}\text { Infant } \\
\text { sex }\end{array}$ & $\begin{array}{l}\text { Infant } \\
\text { weight (g) }\end{array}$ & $\begin{array}{l}\text { Weight } \\
\text { percentile }\end{array}$ & APGAR & NAS \\
\hline 1 & Sertraline & 50 & 26 & $33+2$ & Vaginal & Boy & 2021 & 43 & 9.9 .10 & 4 \\
\hline 2 & Sertraline & 50 & 31 & $39+4$ & $\begin{array}{l}\text { Vaginal } \\
\text { instrumental }\end{array}$ & Girl & 3510 & 59 & 9.10 .10 & 2 \\
\hline 3 & Sertraline $^{a}$ & 50 & 31 & $38+5$ & Vaginal & Boy & 3420 & 50 & 10.10 .10 & NA \\
\hline 4 & Sertraline & 50 & 32 & $39+3$ & Vaginal & Girl & 3610 & 68 & 9.10 .10 & 4 \\
\hline 5 & Sertraline & 100 & 32 & $37+0$ & Vaginal & Boy & 3400 & 74 & 9.10 .10 & NA \\
\hline 6 & Sertraline & 75 & 32 & $37+3$ & Vaginal & Boy & 3330 & 62 & 7.9 .9 & 3 \\
\hline 7 & Sertraline & 75 & 32 & $37+6$ & Planned CS & Girl & 2890 & 32 & 9.10 .10 & 0 \\
\hline 8 & Sertraline & 75 & 32 & $39+0$ & Planned CS & Boy & 3510 & 53 & 9.10 .10 & 2 \\
\hline 9 & Sertraline $^{\mathrm{d}}$ & 75 & 36 & $38+3$ & Vaginal & NA & NA & NA & NA & NA \\
\hline 10 & Sertraline $^{b}$ & 75 & 39 & $39+2$ & Vaginal & Boy & 3150 & 24 & 6.9 .10 & NA \\
\hline 11 & Placebo & 0 & 24 & $38+4$ & Vaginal & Girl & 3300 & 52 & 9.10 .10 & NA \\
\hline 12 & Placebo $^{c}$ & $\underline{75}$ & 28 & $37+4$ & Vaginal & Girl & 3140 & 55 & 7.9.10 & 2 \\
\hline 13 & Placebo & 0 & 29 & $42+3$ & Vaginal & Girl & 3380 & 38 & 9.10 .10 & 7 \\
\hline 14 & Placebo & 0 & 33 & $39+5$ & Vaginal & Girl & 2732 & 6 & 9.10 .10 & 0 \\
\hline
\end{tabular}

GA gestational age at delivery in weeks + days. CS cesarean section. NAS modified neonatal abstinence scale according to Finnegan in Swedish [39]. Data of all included patients apart from the two early dropouts from the placebo group is presented. NA not available

${ }^{\mathrm{a}}$ Treatment discontinued in $2 \mathrm{nd}$ trimester. ${ }^{\mathrm{b}}$ Treatment discontinued in $3 \mathrm{rd}$ trimester. ${ }^{\mathrm{c}}$ Randomized to placebo but active treatment from $2 \mathrm{nd}$ trimester.

${ }^{\mathrm{d}}$ Lacking informed consent for infant data

group was small for gestational age. All other babies were appropriate weight for gestational age. Two babies in the sertraline group and one in the placebo group experienced mild respiratory disorders with no need of neonatal care or respiratory support with continuous positive airway pressure (CPAP) after the initial $20 \mathrm{~min}$ in life. One baby in the sertraline group experienced transient jitteriness at 1 week of age with a normal EEG at check-up.

\section{Discussion}

This study on sertraline concentrations in pregnant women and their infants demonstrates an over 10-fold interindividual variability in sertraline and its metabolite plasma concentrations across the course of the pregnancy (Table 2), supporting previous studies from both pregnant and non-pregnant populations $[7,12,17]$. The intraindividual variability during pregnancy is low, presented in supplemental Fig. 2. We found an

Table 2 Sertraline and desmethylsertraline plasma concentrations

\begin{tabular}{|c|c|c|c|c|c|c|}
\hline & \multirow[t]{2}{*}{$\mathbf{N}$} & \multirow{2}{*}{ 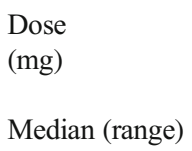 } & \multicolumn{2}{|c|}{$\begin{array}{l}\text { Measured concentration } \\
(\mathrm{ng} / \mathrm{mL})\end{array}$} & \multicolumn{2}{|c|}{ Dose-adjusted concentration $(\mathrm{ng} / \mathrm{mL}) /(\mathrm{mg} /$ day $)$} \\
\hline & & & Median (Q1-Q3) & Range & Median (Q1-Q3) & Range \\
\hline \multicolumn{7}{|l|}{ Sertraline } \\
\hline 2nd trimester & 7 & $50(50-50)$ & $7.65(5.81-12.09)$ & $3.98-17.14$ & $0.15(0.12-0.24)$ & $0.08-0.34$ \\
\hline 3rd trimester & 9 & $50(50-75)$ & $9.49(7.34-17.14)$ & $1.53-20.81$ & $0.19(0.12-0.23)$ & $0.03-0.38$ \\
\hline At delivery & 8 & $75(50-100)$ & $14.38(7.65-18.67)$ & $3.64-24.17$ & $0.19(0.15-0.25)$ & $0.07-0.32$ \\
\hline Postpartum & 8 & $75(50-75)$ & $17.9(8.87-19.35)$ & $6.12-52.02$ & $0.25(0.17-0.29)$ & $0.12-0.69$ \\
\hline \multicolumn{7}{|c|}{ Desmethylsertraline } \\
\hline 2nd trimester & 7 & $50(50-50)$ & $24.25(22.65-32.29)$ & $15.78-10.52$ & $0.49(0.45-0.65)$ & $0.32-0.88$ \\
\hline 3rd trimester & 9 & $50(50-75)$ & $35.06(28.05-55.52)$ & $10.52-61.36$ & $0.70(0.47-0.74)$ & $0.21-1.11$ \\
\hline At delivery & 8 & $75(50-100)$ & $33.60(22.95-46.75)$ & $7.01-61.36$ & $0.46(0.37-0.62)$ & $0.14-0.82$ \\
\hline Postpartum & 6 & $75(50-75)$ & $45.29(28.56-78.89)$ & $16.95-87.66$ & $0.69(0.43-1.05)$ & $0.34-1.17$ \\
\hline
\end{tabular}

Sertraline dose presented as median and range (min-max) and measured and dose-adjusted sertraline and desmethylsertraline plasma concentrations presented as medians, interquartile ranges (Q1-Q3) and ranges (min-max) 
Table 3 Alteration ratios

\begin{tabular}{llll}
\hline Alteration ratio, median (min-max) & 2nd trimester & 3rd trimester & Delivery \\
\hline Sertraline & $0.88(0.49-1.37)$ & $0.69(0.17-1.23)$ & $0.85(0.21-2.08)$ \\
Desmethylsertraline & $0.94(0.47-1.38)$ & $0.89(0.62-1.44)$ & $0.72(0.25-1.22)$ \\
\hline
\end{tabular}

Alteration ratios between pregnant and the non-pregnant state measured 1-month postpartum for sertraline and desmethylsertraline, presented as a median (min-max) of the 8 women with sufficient data

overrepresentation of lower concentrations, with only a few notably higher concentrations as reported in non-pregnant populations, adding to the varying results from studies in pregnant women [7, 12, 17, 42]. This variability is probably due to genetic differences in drug metabolic capacity, mainly caused by the polymorphism of the CYP2C19-enzyme [22, 26]. We also observe an up to 10 -fold variation in the alteration ratios between pregnant and non-pregnant state, with the median ratio just below 1 (Table 3 ). This supports the findings of a recent study and suggests a genetic variation in the pregnancy-induced changes of the drug metabolizing enzymes as well [41]. However, it might also be explained by altered levels of protein binding during pregnancy [21]. The median drug-adjusted sertraline plasma concentration increased by $67 \%$ from the second trimester to postpartum (Table 2, Supplemental Fig. 2). However, probably due to sample size, this was not statistically significant. Based on these findings, together with results from previous studies, it seems wise to monitor plasma sertraline concentrations during and after pregnancy [7, 12, 25, 43].

Median plasma concentrations of sertraline in the infants were found to be around a third of the mother's, suggesting a low placental passage of sertraline. This is in line with findings from a handful earlier studies and is reassuring regarding the safety of sertraline during pregnancy [29-32]. We also found a linearity in this correlation not previously described, presented in the online supplement. The low infant levels might be explained by sertraline mostly being bound to AAP, present in the infant at levels around a third of the mother's. The very high proportion of protein-bound sertraline and its metabolite probably also explains why the sertraline concentration in the infant is low even though the placental permeability for the free form of the drug is markedly increased at the end of the pregnancy. Our results also suggest that in the infant, sertraline is effectively cleared and converted to desmethylsertraline (Fig. 1), which is in line with one previous study showing a total clearance of sertraline at five days of age [31].

Previous studies have shown that both maternal major depression and exposure to SSRIs are associated to increased risks for intrauterine growth restriction, prematurity, and neonatal adaptation problems including jitteriness, respiratory problems, and hypoglycemia [30, 33, 44]. In the present study, none of the nine exposed infants had any signs of asphyxia, intrauterine growth restriction, or poor neonatal adaptation. One infant exposed to sertraline experienced transient jitteriness at 1 week of age and two infants in the sertraline group and one in the placebo group experienced a transient need of respiratory support with CPAP, for less than 20 min. Group sizes were too small to determine whether any of these outcomes are significant. Large postpartum hemorrhage when using SSRI is a known complication [45, 46], and in this small sample, we found a tendency towards increased postpartum hemorrhage in the women treated with sertraline, presented in Section 2.5 of the online supplement.

The main strength of our study is that the indication for the treatment was well-based by the study psychiatrist and same in all patients, which is often not the case in naturalistic studies. As per protocol, the patients also did not have any significant concomitant medications. The greatest limitation of our study turned out to be the sample size, and none of the results is statistically significant. However, previous studies have encountered the same limitation, and increasing the sample sizes to achieve significant results is our common challenge.

As sertraline is highly protein bound, it would have been of great interest to also measure the concentrations of the free drug. This would have had potential to increase our knowledge about the pregnancy changes of sertraline concentrations and the transfer of sertraline to the infant.

Considering SSRIs being such a common treatment during pregnancy, it is a shame that studying its effects is so complicated, with small sample sizes limiting clinical studies and register-based studies struggling with confounding, especially confounding by the severity of the underlying disease. In the online supplement, we are discussing the challenges of RCT:s in this field. We hope that our finding of infant plasma concentrations being just a third of the maternal concentration can bring further assurance to the safety of the use of sertraline during pregnancy. It is also assuring for the safety of the treatment that the repeated measures of maternal concentrations are reasonably stable across the course of the pregnancy.

\section{Conclusions}

In our small cohort, sertraline concentrations during pregnancy do seem lower than the ones postpartum, probably indicating an increased metabolism during pregnancy. However, this is not true for all of the women, supporting the role of genetic differences. Therapeutic drug monitoring during pregnancy 
can increase the safety and efficacy of the treatment on group level, finding the poor metabolizers at risk for elevated drug concentrations with potential to cause adverse effects, as well as the women with low concentrations as a reason to lack of treatment effect. In our study, the infant plasma concentrations were low, and no serious adverse events were found in the included infants. Therefore, based on our material together with previous studies in the field covering the long-term effects $[5,6]$, it seems as if sertraline is safe to use for moderate depression during pregnancy when indicated. Further, collecting novel un-confounded data through randomized trials in this field is very difficult, why register based studies have an important role in future.

Supplementary Information The online version contains supplementary material available at https://doi.org/10.1007/s00228-021-03122-z.

Acknowledgements Our special gratitude goes to Eva-Marie Nordenadler, the psychiatry nurse responsible for all treatment evaluations, gynecologist Barbara Szymanska von Schultz and all our study midwives for supporting the included women throughout the study and making sure the samples were taken at given times. The study psychologists Viktor Kaldo and Erik Forssell who developed the I-CBT treatment protocol, and psychologists Mikaela Bergmark and Sandra Frööjd who monitored the patients during the I-CBT treatment. We are of course also grateful for the cooperation within the whole MAGDALENA study group including the safety and monitoring board consisting of experts in the various specialities that this study involves; all its members have contributed to achieving these results. We would like to acknowledge M Bendix, ML Dahl and C Rück for input on the study protocol at an early phase of the project. We also like to acknowledge all women, their babies and their families who participate in the MAGDALENA study and the numerous midwives, obstetricians, and staff at all recruiting Antenatal Clinics and Maternity Wards and Delivery Units in Stockholm Healthcare Region.

Data and material availability Individual data are protected by the General data protection Regulation in EU (GDPR). All data is stored and accessible in a data repository at the University.

Code availability Not applicable

Authors' contributions $\mathrm{EH}, \mathrm{KW}$, and LLG wrote this manuscript. EH and LLG also wrote the study protocol article for the MAGDALENA study. KW was the principal investigator for this study, and JN, LLG and $\mathrm{MB}$ were members of the governing study board. $\mathrm{MB}$ was the main applicant and receiver of the initial funding decision from the Swedish Research Council and acted as a sponsor for the study. MB is also a senior researcher with full responsibility for the study design and participation in the completion of the manuscript.

$\mathrm{JN}, \mathrm{KW}$, and MB conceived the study protocol and $\mathrm{KW}$ wrote the initial draft of it. MH was the study midwife at the end of the study, who collected and organized all data in the end. M.B-W was the study psychiatrist responsible for the psychiatric assessment regarding inclusion in the study as well as for the clinical decisions about pharmacotherapy during the study period. $\mathrm{EH}$ and $\mathrm{KW}$ designed the data collection forms for the infant outcomes and performed clinical examinations after delivery and made sure that the infant samples were collected. AP and LLG were responsible for the laboratory analyses of plasma sertraline and metabolite concentrations.
All authors have in different ways been involved in various degrees in the development of study design and take responsibility for the final study design.

Funding Open access funding provided by Karolinska Institute. This work was supported by the Swedish Research Council (DNR 5212012-3466), the regional agreement on medical training and clinical research between Karolinska Institutet and Stockholm City Council (ALF, project number 533069 years 2015-2017 and project number 573301 years 2018-2020), Lilla Barnets Fond, Märta Philipssons stiftelse, European Society of Pediatric Research, Stiftelsen Samariten and funds from both Karolinska Institutet (awarded LLG) and the neonatology department at Karolinska University Hospital (awarded EWH). The funding agencies did not have any part in the design, data collection, and analysis or reporting of this trial.

\section{Declarations}

Ethics approval The study was approved by the regional ethical review board in Stockholm (dnr.2014/952-31).

Consent to participate Informed consent to participate was obtained from all participants included in the study for both themselves and their infants. For the infants informed consent to participate was also obtained from the other parent.

Consent to publish Informed consent to publish the results was obtained from all participants included in the study and from the other parent to publish the results regarding the infants.

Competing interests The authors declare no competing interests.

Open Access This article is licensed under a Creative Commons Attribution 4.0 International License, which permits use, sharing, adaptation, distribution and reproduction in any medium or format, as long as you give appropriate credit to the original author(s) and the source, provide a link to the Creative Commons licence, and indicate if changes were made. The images or other third party material in this article are included in the article's Creative Commons licence, unless indicated otherwise in a credit line to the material. If material is not included in the article's Creative Commons licence and your intended use is not permitted by statutory regulation or exceeds the permitted use, you will need to obtain permission directly from the copyright holder. To view a copy of this licence, visit http://creativecommons.org/licenses/by/4.0/.

\section{References}

1. Molenaar NM, Bais B, Lambregtse-Van Den Berg MP, Mulder CL, Howell EA, Fox NS, Rommel A-S, Bergink V, Kamperman AM (2020) The international prevalence of antidepressant use before, during, and after pregnancy: a systematic review and meta-analysis of timing, type of prescriptions and geographical variability. J Affect Disord 264:82-89. https://doi.org/10.1016/j.jad.2019.12. 014

2. Reefhuis J, Devine O, Friedman JM, Louik C, Honein MA, National Birth Defects Prevention S (2015) Specific SSRIs and birth defects: Bayesian analysis to interpret new data in the context of previous reports. BMJ 351:h3190. https://doi.org/10.1136/bmj. h3190

3. Reis M, Kallen B (2010) Delivery outcome after maternal use of antidepressant drugs in pregnancy: an update using Swedish data. 
Psychol Med 40(10):1723-1733. https://doi.org/10.1017/ S0033291709992194

4. Womersley K, Ripullone K, Agius M (2017) What are the risks associated with different selective serotonin re-uptake inhibitors (SSRIs) to treat depression and anxiety in pregnancy? An evaluation of current evidence. Psychiatr Danub 29(Suppl 3):629-644

5. Sujan AC, Rickert ME, Oberg AS, Quinn PD, Hernandez-Diaz S, Almqvist C, Lichtenstein P, Larsson H, D'Onofrio BM (2017) Associations of maternal antidepressant use during the first trimester of pregnancy with preterm birth, small for gestational age, autism spectrum disorder, and attention-deficit/hyperactivity disorder in offspring. JAMA 317(15):1553-1562. https://doi.org/10.1001/ jama.2017.3413

6. Brown HK, Ray JG, Wilton AS, Lunsky Y, Gomes T, Vigod SN (2017) Association between serotonergic antidepressant use during pregnancy and autism spectrum disorder in children. JAMA 317(15):1544-1552. https://doi.org/10.1001/jama.2017.3415

7. Westin AA, Brekke M, Molden E, Skogvoll E, Spigset O (2017) Selective serotonin reuptake inhibitors and venlafaxine in pregnancy: changes in drug disposition. PLoS One 12(7):e0181082. https:// doi.org/10.1371/journal.pone.0181082

8. Sit DK, Perel JM, Helsel JC, Wisner KL (2008) Changes in antidepressant metabolism and dosing across pregnancy and early postpartum. J Clin Psychiatry 69(4):652-658. https://doi.org/10.4088/ jep.v69n0419

9. Freeman MP, Nolan PE Jr, Davis MF, Anthony M, Fried K, Fankhauser M, Woosley RL, Moreno F (2008) Pharmacokinetics of sertraline across pregnancy and postpartum. J Clin Psychopharmacol 28(6):646-653. https://doi.org/10.1097/JCP. 0b013e $31818 \mathrm{~d} 2048$

10. Ruhé HG, Huyser J, Swinkels JA, Schene AH (2006) Dose escalation for insufficient response to standard-dose selective serotonin reuptake inhibitors in major depressive disorder. $\mathrm{Br} \mathrm{J}$ Psychiatry 189(4):309-316. https://doi.org/10.1192/bjp.bp.105.018325

11. DeVane CL, Liston HL, Markowitz JS (2002) Clinical pharmacokinetics of sertraline. Clin Pharmacokinet 41(15):1247-1266

12. Reis M, Åberg-Wistedt A, Ågren H, Höglund P, Åkerblad A-C, Bengtsson F (2004) Serum disposition of sertraline, Ndesmethylsertraline and paroxetine: a pharmacokinetic evaluation of repeated drug concentration measurements during 6 months of treatment for major depression. Hum Psychopharmacol Clin Exp 19(5):283-291. https://doi.org/10.1002/hup.599

13. Jakubovski E, Varigonda AL, Freemantle N, Taylor MJ, Bloch MH (2016) Systematic review and meta-analysis: dose-response relationship of selective serotonin reuptake inhibitors in major depressive disorder. Am J Psychiatr 173(2):174-183. https://doi.org/10. 1176/appi.ajp.2015.15030331

14. Baker CB, Tweedie R, Duval S, Woods SW (2003) Evidence that the SSRI dose response in treating major depression should be reassessed: a meta-analysis. Depress Anxiety 17(1):1-9. https:// doi.org/10.1002/da.10079

15. Hieronymus F, Nilsson S, Eriksson E (2016) A mega-analysis of fixed-dose trials reveals dose-dependency and a rapid onset of action for the antidepressant effect of three selective serotonin reuptake inhibitors. Transl Psychiatry 6(6):e834-e834. https://doi.org/ 10.1038/tp.2016.104

16. Baumann P et al (2005) The AGNP-TDM Expert Group Consensus Guidelines: Focus on therapeutic monitoring of antidepressants. Pharmacol Mood Disord 7(3):231-247. https://doi.org/10.31887/ dens.2005.7.3/pbaumann

17. Lundmark J, Reis M, Bengtsson F (2000) Therapeutic drug monitoring of sertraline : variability factors as displayed in a clinical setting. Ther Drug Monit 22(4):446-454. https://doi.org/10.1097/ 00007691-200008000-00014

18. Murdoch D, McTavish D (1992) Sertraline. Drugs 44(4):604-624. https://doi.org/10.2165/00003495-199244040-00007
19. Ronfeld RASG, Tremaine LM (1988) Distribution and pharmacokinetics of the selective 5-HT uptake blocker sertraline in man, rat and dog. Psychopharmacology 96(Suppl):269

20. Huang Z, Ung T (2013) Effect of alpha-1-acid glycoprotein binding on pharmacokinetics and pharmacodynamics. Curr Drug Metab 14(2):226-238

21. Jeong H (2010) Altered drug metabolism during pregnancy: hormonal regulation of drug-metabolizing enzymes. Expert Opin Drug Metab Toxicol 6(6):689-699. https://doi.org/10.1517/ 17425251003677755

22. Huddart R, Hicks JK, Ramsey LB, Strawn JR, Smith DM, Bobonis Babilonia M, Altman RB, Klein TE (2020) PharmGKB summary: sertraline pathway, pharmacokinetics. Pharmacogenet Genomics 30(2):26-33. https://doi.org/10.1097/FPC.0000000000000392

23. Zhou Y, Ingelman-Sundberg M, Lauschke VM (2017) Worldwide distribution of cytochrome P450 alleles: a meta-analysis of population-scale sequencing projects. Clin Pharmacol Ther 102(4):688-700. https://doi.org/10.1002/cpt.690

24. Obach RS, Cox LM, Tremaine LM (2005) Sertraline is metabolized by multiple cytochrome p450 enzymes, monoamine oxidases, and glucuronyl transferases in human: an in vitro study. Drug Metab Dispos 33(2):262-270. https://doi.org/10.1124/dmd.104.002428

25. Pogliani L, Falvella FS, Cattaneo D, Pileri P, Moscatiello AF, Cheli S, Baldelli S, Fabiano V, Cetin I, Clementi E, Zuccotti G (2017) Pharmacokinetics and pharmacogenetics of selective serotonin reuptake inhibitors during pregnancy: an observational study. Ther Drug Monit 39(2):197-201. https://doi.org/10.1097/ftd. 0000000000000370

26. Saiz-Rodriguez M, Belmonte C, Roman M, Ochoa D, Koller D, Talegon M, Ovejero-Benito MC, Lopez-Rodriguez R, Cabaleiro T, Abad-Santos F (2018) Effect of polymorphisms on the pharmacokinetics, pharmacodynamics and safety of sertraline in healthy volunteers. Basic Clin Pharmacol Toxicol 122(5):501-511. https://doi. org/10.1111/bcpt.12938

27. Ewing G, Tatarchuk Y, Appleby D, Schwartz N, Kim D (2015) Placental transfer of antidepressant medications: implications for postnatal adaptation syndrome. Clin Pharmacokinet 54(4):359 370. https://doi.org/10.1007/s40262-014-0233-3

28. Colombo A, Giordano F, Giorgetti F, Di Bernardo I, Bosi MF, Varinelli A, Cafaro R, Pileri P, Cetin I, Clementi E, Viganò CA, Dell'Osso B (2020) Correlation between pharmacokinetics and pharmacogenetics of selective serotonin reuptake inhibitors and selective serotonin and noradrenaline reuptake inhibitors and maternal and neonatal outcomes: results from a naturalistic study in patients with affec. Hum Psychopharmacol Clin Exp. https://doi. org/10.1002/hup. 2772

29. Hendrick V, Stowe ZN, Altshuler LL, Hwang S, Lee E, Haynes D (2003) Placental passage of antidepressant medications. Am J Psychiatr 160(5):993-996. https://doi.org/10.1176/appi.ajp.160.5. 993

30. Paulzen M, Goecke TW, Stickeler E, Grunder G, Schoretsanitis G (2017) Sertraline in pregnancy - Therapeutic drug monitoring in maternal blood, amniotic fluid and cord blood. J Affect Disord 212:1-6. https://doi.org/10.1016/j.jad.2017.01.019

31. Rampono J, Proud S, Hackett LP, Kristensen JH, Ilett KF (2004) A pilot study of newer antidepressant concentrations in cord and maternal serum and possible effects in the neonate. Int $\mathrm{J}$ Neuropsychopharmacol 7(3):329-334. https://doi.org/10.1017/ s1461145704004286

32. Rampono J, Simmer K, Ilett KF, Hackett LP, Doherty DA, Elliot R, Kok CH, Coenen A, Forman T (2009) Placental transfer of SSRI and SNRI antidepressants and effects on the neonate. Pharmacopsychiatry 42(3):95-100. https://doi.org/10.1055/s0028-1103296

33. Norby U, Forsberg L, Wide K, Sjors G, Winbladh B, Kallen K (2016) Neonatal morbidity after maternal use of antidepressant 
drugs during pregnancy. Pediatrics 138(5):e20160181. https://doi. org/10.1542/peds.2016-0181

34. Moses-Kolko EL, Bogen D, Perel J, Bregar A, Uhl K, Levin B, Wisner KL (2005) Neonatal signs after late in utero exposure to serotonin reuptake inhibitors: literature review and implications for clinical applications. JAMA 293(19):2372-2383. https://doi.org/ 10.1001/jama.293.19.2372

35. Heinonen E, Szymanska-von Schultz B, Kaldo V, Nasiell J, Andersson E, Bergmark M, Blomdahl-Wetterholm M, Forsberg L, Forsell E, Forsgren A, Froojd S, Goldman A, Nordenadler EM, Sklivanioti M, Blennow M, Wide K, Gustafsson LL (2018) MAGDALENA: study protocol of a randomised, placebocontrolled trial on cognitive development at 2 years of age in children exposed to SSRI in utero. BMJ Open 8(8):e023281. https:// doi.org/10.1136/bmjopen-2018-023281

36. Forsell E, Bendix M, Hollandare F, Szymanska von Schultz B, Nasiell J, Blomdahl-Wetterholm M, Eriksson C, Kvarned S, Lindau van der Linden J, Soderberg E, Jokinen J, Wide K, Kaldo $\mathrm{V}$ (2017) Internet delivered cognitive behavior therapy for antenatal depression: a randomised controlled trial. J Affect Disord 221:56 64. https://doi.org/10.1016/j.jad.2017.06.013

37. First, M. B., \& Gibbon, M. (2004). The Structured Clinical Interview for DSM-IV Axis I Disorders (SCID-I) and the Structured Clinical Interview for DSM-IV Axis II Disorders (SCID-II). In M. J. Hilsenroth \& D. L. Segal (Eds.), Comprehensive handbook of psychological assessment, Vol. 2. Personality assessment (p. 134-143). John Wiley \& Sons Inc.

38. Montgomery SA, Asberg M (1979) A new depression scale designed to be sensitive to change. Br J Psychiatry 134:382-389

39. Forsberg L, Naver L, Gustafsson LL, Wide K (2014) Neonatal adaptation in infants prenatally exposed to antidepressantsclinical monitoring using Neonatal Abstinence Score. PLoS One 9(11):e111327. https://doi.org/10.1371/journal.pone.0111327
40. National Center for Biotechnology Information (2020) PubChem Compound Summary for CID 68617 SRS, 2020 from https:// pubchem.ncbi.nlm.nih.gov/compound/Sertraline

41. Schoretsanitis G, Spigset O, Stingl JC, Deligiannidis KM, Paulzen M, Westin AA (2020) The impact of pregnancy on the pharmacokinetics of antidepressants: a systematic critical review and metaanalysis. Expert Opin Drug Metab Toxicol 16(5):431-440. https:// doi.org/10.1080/17425255.2020.1750598

42. Deligiannidis KM, Byatt N, Freeman MP (2014) Pharmacotherapy for mood disorders in pregnancy: a review of pharmacokinetic changes and clinical recommendations for therapeutic drug monitoring. J Clin Psychopharmacol 34(2):244-255. https://doi.org/10. 1097/JCP.0000000000000087

43. Svensson M, Reimers A, Reis M (2020) [Pharmacokinetics of antidepressants during pregnancy]. Lakartidningen 117

44. Källén B (2004) Neonate characteristics after maternal use of antidepressants in late pregnancy. Arch Pediatr Adolesc Med 158(4): 312-316. https://doi.org/10.1001/archpedi.158.4.312

45. Lindqvist PG, Nasiell J, Gustafsson LL, Nordstrom L (2014) Selective serotonin reuptake inhibitor use during pregnancy increases the risk of postpartum hemorrhage and anemia: a hospitalbased cohort study. J Thromb Haemost 12(12):1986-1992. https:// doi.org/10.1111/jth.12757

46. Skalkidou A, Sundstrom-Poromaa I, Wikman A, Hesselman S, Wikstrom AK, Elenis E. SSRI use during pregnancy and risk for postpartum haemorrhage: a national register-based cohort study in Sweden. BJOG 2020;127:1366-1373.

Publisher's note Springer Nature remains neutral with regard to jurisdictional claims in published maps and institutional affiliations. 